\title{
SELECTED OUTCOMES OF RESEARCH OF DIGITAL COMPETENCY DEVELOPMENT ON ELEMENTARY SCHOOLS
}

\author{
Vladimír Rambousek, Viktor Fuglík, Jiří Štípek
}

Charles University in Prague

\begin{abstract}
Highlights
- Identification of opinions and teachers' experience with the development of digital competence

- Analysis ways of implementation of digital competences into the educational environment of schools
\end{abstract}

\begin{abstract}
The paper provides a summary report on the concept and outcomes of the survey for teachers of informatics subjects and of the case studies of the implementation of information technologies and the development of digital competencies in educational activities, which were used as complementary research methods within the research project focused on a complex issue of curricular, process and organizational aspects of digital literacy education in primary and lower-secondary schools in the Czech Republic. The main research methods of the project were the questionnaires for teachers and pupils, by means of which relevant data from 1183 schools and from 2,507 pupils were obtained. In the second phase of research the survey on 167 schools was applied and 6 case studies were conducted in selected schools. The purpose of the survey and case studies was to supplement other applied methods by an observation, a discussion and an interview in the school environment and to complete the findings of the whole research.
\end{abstract}

\author{
Article type \\ Full research paper \\ Article history \\ Received: May 25, 2015 \\ Received in revised form: June 18, 2015 \\ Accepted: June 28, 2015 \\ Available on-line: June 30, 2015
}

\section{Keywords}

School education, digital literacy education, ICT skills, development of ICT competencies

Rambousek V., Fuglik V. and Štipek J. (2015) "Selected Outcomes of Research of Digital Competency Development on Elementary Schools", Journal on Efficiency and Responsibility in Education and Science, Vol. 8, No. 2, pp. 35-43, online ISSN 1803-1617, printed ISSN 2336-2375, doi: 10.7160/eriesj.2015.080201.

\section{Introduction}

The ability to operate and use contemporary information and communication technologies and the development of digital competence has become increasingly important for the labor market, both in terms of working means and obtaining qualifications. Mastery of relevant technological competencies is already recognized as a factor that improves one's position in the labor market, as well as when gaining or changing qualifications. In information societies based on information and communication technologies (ICT) and knowledge, education and training have become a necessary condition for the success of individuals, as well as the basic characteristics of the developing society itself (European Commission, 2008).

If the above declared facts indicate that the future success of individuals may be largely dependent upon their level of digital competence, then access to technology, and the opportunity to learn how to use it, should be available to the broadest possible extent. This again implies a need to integrate ICT and the development of digital competence (in conjunction with the development of critical and creative thinking, problem solving abilities, informatics-based thinking and student creativity) into the educational content and processes utilized in schools and lifelong learning systems (Ala-Mutka, Punie and Redecker, 2008). This integration is emphasized on a long-term basis in strategic, conceptual and curriculum-based documents (UNESCO, 2005), and is therefore a current priority in the educational strategies of developed countries (European Commission, 2013).

The development of digital competence, whether implemented in primary school, in other forms of initial education, or even further education, targets at the entity of the respective educational impact and the corresponding level of digital literacy. Generally speaking, competencies are understood to be an integrated, portable and multifunctional set of knowledge, cognitive and practical skills, attitudes and values representing the potential to perform effectively in a given context, which can be utilized as a whole to enable efficient conduct of a given individual (OECD DeSeCo, 2005). The 2006 European Parliament recommendations for key competencies for lifelong learning (European Parliament and the Council, 2006), lists "Digital competence" as being fourth place among these competencies, and is defined as the confident and critical use of Information Society Technology (IST) for work, leisure and communication.

Undoubtedly, one of the most significant of studies, which focused on specifications of a given competency and its components, was the Digital Competence Project (DIGCOMP), which was carried out by the Institute for Prospective Technological Studies (an institute of the European Commission - Joint Research Center) between 2011 and 2012 (Ferrari, 2013). Contemporary, in project declared, definition of the concept of digital competence and digital literacy based on understanding and interpretation of digital competence and digital literacy was based on the understanding of key competencies such as the ability to use relevant knowledge and skills with responsibility and autonomy, while utilizing a creative, critical and intercultural approach in relation to work, leisure and education (Ala-Mutka, 2011). 
Based on an analysis of various definitions of the respective key competencies, a basic digital competence framework was created. This framework includes not only technical skills, but also relevant knowledge and attitudes. The basic framework comprises 7 subareas of competence (Ala-Mutka, 2011, p. 4): Information management, Collaboration, Communication and sharing, Creation of content and knowledge, Ethics and Responsibility, Evaluation and Problem-solving and Technical operations.

A report from the DIGCOMP project presented a general framework for relevant key competencies and their related sub-competencies. More specifically, it presented the following 5 areas and 21 sub-competencies that characterize skills and attitudes in terms of necessary knowledge (Ferrari, 2013):

1. Information: 1.1 Browsing, searching and filtering information; 1.2 Evaluating Information; 1.3 Storing and retrieving information

2. Communication: 2.1 Interacting through technologies; 2.2 Sharing information and content; 2.3 Engaging in online citizenship; 2.4 Collaborating through digital channels; 2.5 Netiquette; 2.6 Managing digital identity

3. Content creation: 3.1 Developing content; 3.2 Integrating and re-elaborating; 3.3 Copyright and Licences; 3.4 Programming

4. Safety: 4.1 Protecting devices; 4.2 Protecting personal data; 4.3 Protecting health; 4.4 Protecting the environment

5. Problem solving: 5.1 Solving technical problems; 5.2 Identifying needs and technological responses; 5.3 Innovative and creative use of technology; 5.4 Identifying digital competence gaps

The concept of Digital Literacy has already been used alongside other concepts for a number of years. Recently, however, it has become a dominant term in professional terminology and is often used in strategic and conceptual materials. The contemporary concept of digital literacy is directly related to the definition of digital competence as a set of knowledge, skills and attitudes which includes relevant qualifications, strategies and values (Ferrari, 2012). Digital literacy is, therefore, conceived as a concept that comprises the following three primary areas (AlaMutka, 2011, p. 46):

- Instrumental knowledge and skills for effective use of digital tools and resources;

- Advanced knowledge and skills for communication and collaboration, information management, learning, problem solving and meaningful participation;

- Attitudes to the strategic use of intercultural, critical and creative skills in a responsible and autonomous manner.

Digital literacy is a very broad concept which, to varying degrees, overlaps with other literacy concepts that contain partial information technology and digital components.

The above stated facts underline the importance of modern, competence-orientated information technology education provided within elementary education. Yet, they also stress the need for research activities seeking to explore the current state and approach of the development of pupils' information technology competencies in primary and lower-secondary schools. In this context, researchers from the Faculty of Education, Charles University in Prague realized research project P407-12-1541 "Pupils' Information Technology Competencies and Their Development in Primary and Lower-secondary Schools", supported by the Czech Science Foundation grant.
The research focused on the issue of informatics, or digital literacy education in Czech primary (ISCED 1) and lowersecondary (ISCED 2) schools and its target group included both the teachers of informatics subjects and their pupils. More than 1000 primary and lower-secondary schools from all regions of the Czech Republic joined the project through their teachers and pupils (Rambousek et al, 2013; Rambousek, Štípek and Wildová, 2015).

The issue of informatics, or digital literacy education in Czech primary and lower-secondary schools seen from the viewpoint of curricular, process and organizational aspects was the subject of the research activity within the project. Five main areas of interest representing key dimensions of a coherent survey were identified within the subject thus broadly defined. The subject of research was so broken down into five problem areas focused on the: (a) characteristics of informatics learning activities, (b) content of informatics learning activities, (c) current state and concept of pupils' information technology competencies development, (d) structure of teachers' ICT competencies, and (e) implementation of information technology competencies development into learning activities and educational school environment (Štípek, Rambousek and Procházka, 2013a). The primary aim of the project was defined as the identification of the current state, structure and orientation of the development of pupils' digital, or information technology competencies in terms of building the level of their digital literacy (Štípek, Rambousek and Procházka, 2013b).

\section{Material and Methods}

During the project, within an extensive exploratory survey, both empirical quantitative and qualitative methods were used in addition to theoretical methods. The questionnaire method was used as a primary empirical research method. It was based on an interactive graphic questionnaire for teachers of informatics subjects, in which research data were obtained from 1183 teachers representing individual primary and lower-secondary schools. Questionnaire was also applied for pupils. This questionnaire was completed by 2,173 pupils from 112 primary schools (Rambousek et al, 2013; Rambousek, Štípek, Procházka and Wildová, 2014).

The questionnaire for teachers also included an invitation to participate in the second empirical phase of the research based on a survey for teachers and case studies. 167 teachers of informatics subjects, $52 \%$ of whom were women, $48 \%$ men, representing 167 primary and lower secondary schools accepted the invitation and registered into the system.

In the second phase of the project, whose findings are the subject of this paper, the survey method and the method of case studies were applied.

\section{The survey}

Through the survey respondents could express their views and experiences with curricular, process and organizational aspects of digital literacy education and the development of digital competences of pupils in primary schools. The survey included five thematic fields, three of which included sub-questions. There were all together nine questions in the survey (Rambousek and Štípek, 2014):

The first thematic area focused on the evaluation of the approach of the Framework Educational Programme for Elementary Education (FEP EE) in the educational field of Information and Communication Technologies. It included two questions: 
1.a) What is your assessment of the current FEP EE in the educational field of Information and Communication Technologies?

1.b) How would you modify this document in the given field? The second thematic area of the survey focused on the findings as to how the respondents modified the educational field of Information and Communication Technologies when defining their School Educational Programme. It included one question:

2) How did you extend or modify the given field in your School Educational Programme (SEP), or what is specific in your SEP compared to the FEP EE approach?

The third thematic area of the survey sought to find out how the respondents perceive the compulsory informatics subject in terms of its inclusion in the school curriculum, mainly in terms of its time allocation. It included one question:

3) How do you perceive the compulsory informatics subject in terms of its inclusion and time allocation?

The fourth field of the survey focused on the evaluation of the results of information technology competencies development and on the definition of the conditions for successful educational impact. It included three questions:

4.a) How do you manage to achieve the goals and intentions of SEP in terms of building and developing pupils' information technology competencies and how do other subjects and school environment contribute to that?

4.b) What do you consider a necessary condition for achieving the goals and intentions of SEP in terms of building and developing pupils' information technology competencies?

4.c) What do you consider the main obstacle to achieving the goals and intentions of SEP in terms of building and developing pupils' information technology competencies?

The fifth thematic field focused on the methods and organisation of teaching informatics subjects. It included two questions:

5.a) What is the usual course of the lesson of the compulsory informatics subject from the viewpoint of teaching methods and organisation of education?

5.b) What has proved successful in developing pupils' information technology competencies and could provide an inspiration for others?

The survey was electronically assigned to the teachers interested in the participation in the second phase of the research, into which 167 schools registered. 84 teachers of informatics subjects $(48 \%$ women and $52 \%$ men), which corresponds to a response rate of $50.3 \%$, expressed their opinions and experience concerning information technology education and the development of pupils' information technology competencies in primary and lower-secondary schools.

Within individual questions and sub-questions, the obtained qualitative data were prepared for the analysis by the reduction technique and highlighting the key words in the text. The data thus in-vivo coded were consequently analyzed through the method of cluster analysis, during which the respondents' statements were grouped by their similarity. In this phase of analysis, one respondent's answer could be evaluated as a source of more than one statement. In individual questions, the clusters of similar statements were identified covering the same opinion. The clusters of statements were categorized and given a provisional name. It was not possible to group all the statements, or respondents' answers. There were only a few of such answers, though.

The answers to individual questions, or sub-questions were divided into 4 to 6 clusters following the above described method. Each cluster can provide a number of respondents' statements $\left(n_{v}\right)$ pointing at what is expressed by the given cluster. We may show $n_{v}$, the relative value, expressed percentually based on the total of all the statements of the given question (subquestion). $n_{v}$ value cannot be directly related to the significance of the given cluster compared to the others, though (Rambousek and Štípek, 2014).

\section{Case studies}

Six primary and lower-secondary schools were randomly selected from the 167 registered schools interested in the cooperation. They were asked to consent to carry out the case studies. Six case studies were subsequently realized, two of which in schools in Prague, and one in each of the following regions: Plzeň, Ústí nad Labem, Olomouc, and Moravia-Silesia (Rambousek et al, 2013; Fuglík, 2014).

The method of case studies of ICT implementation and the development of digital competencies into educational activities and a school educational environment was used as a supplementary method in the second stage of the research in six schools. The research took place in one class in Year 3, Year 5 and Year 6 and then three classes in Year 9. The purpose of the case studies was to supplement other applied method by an observation, a discussion and an interview directly in the school environment and partly complement the research findings. The case studies were hence based on the same theoretical foundations and approaches as the whole project. The scenario of the case studies consisted of four blocks: school tours, classroom observations, and discussions with pupils and an interview with a teacher. Each case study block was realized and technically documented by a researcher accompanied by, or helped by a teacher of informatics subjects, or a representative of the school leadership.

From the methodology perspective, the methods of an observation, discussion and interview were primarily used within the qualitative empirical research in schools. Familiarization with the school environment was characterized by an open observation (the teacher knew the role and intention of the researcher) and a participative observation (the researcher got involved in the tour with the aim to get familiar with the school environment as best as possible). The classroom observation was realized as covert in relation to pupils (the researcher pretended to be a newly qualified teacher from a different school), non-participative, structured and in a natural context. The discussion was conducted as a group interview and usually with the same pupils as the previous observation in the lesson with a teacher present. The researcher introduced the issue to the pupils and he or she encouraged them to participate in the discussion following the pupils' spontaneous interest. The interview with a teacher was conducted as semistructured. The beginning was unstructured; gradually it focused on in advance prepared topics. The end of the interview was usually informal. From the viewpoint of typology, descriptive case studies of the organizations and institutions were included with the aim to provide a description of the given phenomenon. The intention of the research was a description of a particular phenomenon in education reality.

\section{School tour}

- Familiarization with the school environment

- Familiarization with the school technical equipment

The first block of the case study consisted of a school tour, during which the researcher got familiar with the school 
environment, or the environment of common areas, classrooms and special classrooms and school technical equipment. In terms of the technical equipment, the following were of special interest: the current state and solution of computer networks and access to the Internet and the devices connected to the networks, and projection and interactive technologies. The first block was hence directly related to the fifth area of the research exploration in terms of identifying the ways and directions of the implementation of ICT into the school educational environment.

\section{Classroom observation}

\section{- The application of the observation scheme}

The second block of the case study comprised a classroom observation of a compulsory informatics subject, which usually included one or two lessons based on the current timetable of the visited schools. During these lessons, regular teaching was going on. The selection of the classes was random and followed the teacher's schedule on the day of the researcher's visit. In advance prepared observation scheme was used to capture the content of the lessons. The organization of teaching and applied methods, pupil's activity and overall atmosphere were monitored. The second block of the case study was hence directly linked to the third area of exploration in terms of the way of monitoring, or the teaching methods and organization, by means of which the pupils' information technology competencies are developed. It was also implicitly linked to the all other areas of exploration.

3. Discussions with pupils

- What does it mean to you to be able to work with a computer?

- Do you think you can already work with a computer? Is it sufficient?

- Do you enjoy informatics at school?

- Why do you like it, what's good about it?

- Why don't you like it, what's bad about it?

- What have you missed in the subject so far?

- Should informatics be taught in schools at all?

The third block of the case study consisted of discussions with pupils, within which the pupils' opinions on the lessons of the informatics subject were found out and they were also asked how they would evaluate their lessons. More specifically, the discussion was conducted by means of targeted questions from the researcher. The discussions took approximately thirty minutes. Printed cards with fourteen thematic units were especially helpful to younger pupils in the discussions concerning mainly the learning content. The third block of the case study was related to the first area of exploration considering the completion of the characteristics of informatics subjects, and also to the second area of exploration in terms of the content of informatics subjects. Directly, it was related to the third area of exploration focusing on the concept of the process and evaluation of the results of the information technology competencies development of the pupils in primary and lowersecondary schools.

4. Interview with a teacher

- Information technology education in School Educational Programmes

- Implementation of ICT into school educational activities

- Methodology approaches to the development of digital competencies

- Level and directions of teachers' development in the area of using ICT in teaching

\section{- School ICT infrastructure and future plans}

The fourth block of the study comprised an interview with a teacher of informatics subjects concerning the issues of the school approach to using technologies and their implementation within SEP, availability and ICT use in the learning process, pupils' and teachers' information technology competencies and the ICT level of school infrastructure. The conduction of the interview was based on in advance prepared topics. During the interview, which took one to two hours, the emphasis was put on the prepared topics but also on the observed events in the course of the whole school visit and on the questions, for which there was not sufficient time during the school tour.

\section{Results}

In the following parts, we present the results of the analysis of respondents' answers to the survey questions and outcomes of case studies.

\section{The survey}

In each question (sub-question) we show obtained clusters of statements given a provisional name and $n_{v}$ value and its relative value (Rambousek et al, 2013; Rambousek and Štípek, 2014).

In the answers to question 1.a) the following clusters of statements were indicated (Table 1).

\begin{tabular}{|l|c|c|}
\hline Clusters sub-question 1.a) & $n_{v}$ & $\%$ \\
\hline 1.a1) I am fine with it & 25 & 41.7 \\
\hline 1.a2) Appropriately general & 6 & 10.0 \\
\hline 1.a3) Too general & 8 & 13.3 \\
\hline 1.a4) Insufficient in content & 14 & 23.3 \\
\hline 1.a5) Insufficient in concept & 7 & 11.7 \\
\hline Sum & $\mathbf{6 0}$ & $\mathbf{1 0 0 . 0}$ \\
\hline
\end{tabular}

Table 1: Clusters sub-question 1.a)

For sub-question 1.a) surprisingly a great number of respondents" statements $(41.7 \%)$ in cluster 1.a1) expressed agreement with the concept and content of the document. Moreover, in the same sense $10 \%$ of statements approve of the general (unrestrictive) concept of the document. Unlike the previous statements, $13.3 \%$ of statements of cluster $1 . a 3$ ) consider the document content as too general, brief and unclear. Besides, two more clusters of statements were formulated considering the concept of the document as insufficient. The first cluster 1.a4) $(23.3 \%)$ emphasizes the insufficient content of the document not reflecting the current state of ICT field and requirements for pupils' information technology competencies development. The statements of the second cluster 1.a5) (11.7\%) are even more critical and they find the whole concept of the document inadequate.

In the answers to 1.b) question the following clusters of statements were indicated (Table 2).

\begin{tabular}{|l|c|c|}
\hline Clusters sub-question 1.b) & $n_{v}$ & $\%$ \\
\hline 1.b1) Increase time allocation & 17 & 27.4 \\
\hline 1.b2) Develop into standards & 16 & 25.8 \\
\hline 1.b3) Content extension & 14 & 22.6 \\
\hline 1.b4) Content innovation & 9 & 14.5 \\
\hline 1.b5) No modifications & 6 & 9.7 \\
\hline Sum & $\mathbf{6 2}$ & $\mathbf{1 0 0 . 0}$ \\
\hline
\end{tabular}

Table 2: Clusters sub-question 1.b)

In relation to sub-question 1.b) the respondents' statements requiring the increase of the current time allocation appeared 
most often in cluster 1.b1) (27.4\%). The second biggest number of statements (25.8\%) in cluster 1.b2) suggest the content be better specified and elaborated into binding standards for individual thematic units. In the context with cluster 1.a4) $22.6 \%$ of statements of cluster 1.b3) perceive the need to extend the document content primarily in the direction of algorithmic thinking development, basics of programming, mobile technologies, working in the cloud and technological support of the cooperation. $14.5 \%$ of statements point out the necessity to innovate the current document content (1.b4) and 9.7\% do not require any modifications.

In the answers to 2) question the following clusters of statements were indicated (Table 3).

\begin{tabular}{|l|c|c|}
\hline Clusters sub-question 2) & $n_{v}$ & $\%$ \\
\hline 2.1) Enriching the curriculum & 32 & 39.0 \\
\hline 2.2) New topics & 7 & 8.5 \\
\hline 2.3) More lessons & 22 & 26.8 \\
\hline 2.4) More details & 5 & 6.1 \\
\hline 2.5) No specifics & 16 & 19.6 \\
\hline Sum & $\mathbf{8 2}$ & $\mathbf{1 0 0 . 0}$ \\
\hline
\end{tabular}

Table 3: Clusters sub-question 2)

The statements $(39.0 \%)$ declaring extending and enriching the curriculum constituted the biggest cluster 2.1) in question 2). The topics such as algorithmization and programming, graphics editing, digital photography and videos, but also typing with all ten fingers appear most often. 8.5\% of statements (2.2) support this direction and they encourage introducing new topics, such as cloud solutions, social networks and the use of mobile devices. The request for a time allocation increase included in cluster 1.b1) became evident in the frequency of statements constituting cluster 2.3 ), in which $26.8 \%$ of statements tell that there have been an increase in the time allocation for informatics subjects and topics by means of cross-subject links and optional subjects. Some of the respondents tried to meet the requirement of the development of the content into topics and outcomes 1.b2) within SEP, which is shown by $6.1 \%$ of statements. The remaining $19.6 \%$ of statements do not state any specifics in this question.

In the answers to question 3) the following clusters of statements were indicated (Table 4).

\begin{tabular}{|l|c|c|}
\hline Clusters sub-question 3) & $n_{v}$ & $\%$ \\
\hline 3.1 Insufficient time allocation & 47 & 47.5 \\
\hline 3.2 Extended time allocation & 21 & 21.2 \\
\hline 3.3 Sufficient time allocation & 14 & 14.1 \\
\hline 3.4 Subject necessary & 17 & 17.2 \\
\hline Sum & $\mathbf{9 9}$ & $\mathbf{1 0 0 . 0}$ \\
\hline
\end{tabular}

Table 4: Clusters sub-question 3)

In question 3, most statements (47.5\%) in cluster 3.1) reflect the opinion that the time allocation for a compulsory subject is too low and it does not reflect the rapid development in the field of information technologies and new requirements for the development of pupils' information technology competencies. $21.2 \%$ of statements in 3.2) cluster express the same opinion, in which respondents state that they extended the low time allocation by means of extra lessons or merging informatics topics with other subjects. Only $14.1 \%$ of statements in 3.3 ) cluster hold the opinion that the time allocation is sufficient. $17.2 \%$ of statements in 3.4) cluster commented on the issue of the existence of a compulsory informatics subject in the school curriculum. All these statements point out the importance of the subject as the base for information technology literacy development. They encourage and at the same time demand a wider interconnection between application informatics topics and other subjects.

In the answers to question 4.a) the following clusters of statements were indicated (Table 5).

\begin{tabular}{|l|c|c|}
\hline Clusters sub-question 4a) & $n_{v}$ & $\%$ \\
\hline 4.a1) I do manage & 46 & 51.1 \\
\hline 4.a2) I manage satisfactorily & 11 & 12.2 \\
\hline 4.a3) Other subjects help & 23 & 25.6 \\
\hline 4.a4) Other subjects do not help & 7 & 7.8 \\
\hline 4.a5) Cannot say & 3 & 3.3 \\
\hline Sum & $\mathbf{9 0}$ & $\mathbf{1 0 0 . 0}$ \\
\hline
\end{tabular}

Table 5: Clusters sub-question 4a)

In sub-question 4.a) the respondents' statements formed 5 clusters. The biggest cluster $4 . \mathrm{a} 1)$ contains $51.1 \%$ of statements declaring that they manage to achieve the given goals and intentions. $12.2 \%$ of statements in cluster $4 . \mathrm{a} 2$ ) support this statement though less definitely. The statements in cluster 4.a3) emphasize (25.6\%) a significant influence of other subjects on the development of pupils' information technology competencies, whereas the statements of cluster 4.a4) express the opposite evaluation (7.8\%). Several statements emphasized that due to the lack of criteria it is not possible to successfully evaluate the achievement of goals (3.3\%).

In the answers to question 4.b) the following clusters of statements were indicated (Table 6).

\begin{tabular}{|l|c|c|}
\hline Clusters sub-question 4b) & $n_{v}$ & $\%$ \\
\hline 4.b1) Adequate equipment & 38 & 39.2 \\
\hline 4.b2) Qualified teachers & 31 & 32.0 \\
\hline 4.b3) Sufficient time allocation & 11 & 11.3 \\
\hline 4.b4) Pupils' interest & 10 & 10.3 \\
\hline $\begin{array}{l}\text { 4.b5) Colleagues' and leader- } \\
\text { ship support }\end{array}$ & 7 & 7.2 \\
\hline Sum & $\mathbf{9 7}$ & $\mathbf{1 0 0 . 0}$ \\
\hline
\end{tabular}

Table 6: Clusters sub-question 4b)

In sub-question $4 \mathrm{~b}$ ) the clusters of statements indicated a necessary condition for achieving the goals and intentions of SEP from the viewpoint of building and developing pupils' information technology competencies. The available, functional and efficient technical equipment reflecting the development in the field of information technologies is the most often stated condition $(4 . b 1,39.2 \%)$. 4.b2) is the second cluster of statements with the highest frequency, in which $32.0 \%$ of statements consider high-quality, qualified teachers with a high level of expertise as a necessary condition. In the context with the previous questions, surprisingly only $11.3 \%$ of statements consider an adequate time allocation (4.b3) a necessary condition and $10.3 \%$ of statements consider pupils' interest and openness (4.b4) a necessary condition. The last cluster 4.b5) formed by $7.2 \%$ of statements points out the necessity of support and helpfulness from the school leaders and whole teaching staff.

In the answers to question 4.c) the following clusters of statements were indicated (Table 7). 
Rambousek V., Fuglik V. and Štípek J. - ERIES Journal vol. 8 no. 2

\begin{tabular}{|l|c|c|}
\hline Clusters sub-question 4c) & $n_{v}$ & $\%$ \\
\hline $\begin{array}{l}\text { 4.c1) Little funding, bad } \\
\text { equipment }\end{array}$ & 31 & 36.9 \\
\hline $\begin{array}{l}\text { 4.c2) Low teachers' } \\
\text { competencies }\end{array}$ & 17 & 20.2 \\
\hline $\begin{array}{l}\text { 4.c3) Low time allocation and } \\
\text { importance }\end{array}$ & 13 & 15.5 \\
\hline 4.c4) Pupils' lack of interest & 13 & 15.5 \\
\hline $\begin{array}{l}\text { 4.c5) Weak support from the } \\
\text { colleagues and leadership }\end{array}$ & 10 & 11.9 \\
\hline Sum & $\mathbf{8 4}$ & $\mathbf{1 0 0 . 0}$ \\
\hline
\end{tabular}

Table 7: Clusters sub-question 4c)

The respondents' statements in sub-question 4.c) formed actually the same clusters as in subquestion 4.b), though expressed in the opposite way. From the viewpoint of the number of statements $(36.9 \%)$ cluster $4 . c 1)$ takes the first place here, in which the respondents consider bad and obsolete equipment and the lack of funds for its renovation or innovation as the main obstacle. Statements (20.2\%) of 4.c2) cluster consider low teachers' competencies, their insufficient qualification, but also insufficient commitment and zeal for teaching as an obstacle. From the viewpoint of the number of statements $(15.5 \%)$ cluster 4.c3) indicates a low time allocation and low interest in the given field of FEP as the third obstacle. The same number of statements (15.5\%) also point out in 4.c4) pupils' lack of interest, passivity and reluctance to acquire a wider spectrum of information technology competencies. $11.9 \%$ of statements in cluster 4.c5) consider weak support and unhelpfulness from the leadership and colleagues as yet another obstacle.

In the answers to question 5.a) the following clusters of statements were indicated (Table 8).

\begin{tabular}{|l|c|c|}
\hline Clusters sub-question 5a) & $n_{v}$ & $\%$ \\
\hline $\begin{array}{l}\text { 5.a1) Combination of methods } \\
\text { and forms }\end{array}$ & 28 & 34.1 \\
\hline 5.a2) Introducing practical work & 23 & 28.0 \\
\hline 5.a3) Emphasis on outcome & 18 & 22.0 \\
\hline 5.a4) Emphasis on technology & 13 & 15.9 \\
\hline Sum & $\mathbf{8 2}$ & $\mathbf{1 0 0 . 0}$ \\
\hline
\end{tabular}

Table 8: Clusters sub-question 5a)

Respondents' statements formed in sub-question 5.a) 4 clusters. In cluster 5.a1), there were $34.1 \%$ of statements, in which respondents characterize their teaching as a combination of various methods and forms, often in terms of traditionally taught lesson. By means of statements in cluster 5.a2) (28.0\%) respondents say that they try to encourage pupils' practical work, or explain the rules and assign the task which the pupils do individually. $22.0 \%$ of statements of cluster 5.a3) moreover emphasize the significance of the outcomes of practical work, which should be familiar, interesting and useful in practice for the pupil. The fourth cluster 5.a4) includes statements (15.9\%), in which respondents accent the importance of technical equipment for their teaching, mainly for classroom work, where each pupil has his or her computer and where a digital projector is available, or interactive whiteboard.

In the answers to question 5.b) the following clusters of statements were identified (Table 9).

\begin{tabular}{|l|c|c|}
\hline Clusters sub-question 5b) & $n_{v}$ & $\%$ \\
\hline $\begin{array}{l}\text { 5.b1) Individual work and } \\
\text { approach }\end{array}$ & 17 & 27.4 \\
\hline $\begin{array}{l}\text { 5.b2) Pupils' interest and } \\
\text { outcomes for practice }\end{array}$ & 13 & 21.0 \\
\hline 5.b3) Cooperation and projects & 9 & 14.5 \\
\hline 5.b4) Materials for pupils & 8 & 12.9 \\
\hline 5.b5) Technologies & 8 & 12.9 \\
\hline 5.b6) Update of the content & 7 & 11.3 \\
\hline Sum & $\mathbf{6 2}$ & $\mathbf{1 0 0 . 0}$ \\
\hline
\end{tabular}

Table 9: Clusters sub-question 5b)

In the last sub-question 5.b) a greater variability of the statements was apparent than in the previous sub-question. According to the statements in cluster 5.b1 (27.4\%) respondents welcome implementing pupils' individual practical work and individual approach to them. By means of the statements in cluster 5.b2) (21.0\%), the respondents say that they had good results when encouraging pupils' interest by implementing pupils' familiar and in practice useful topics as outcomes of practical work. $14.5 \%$ of statements of cluster 5.b3) underline the use of cooperative work and realization of projects, whereas $12.9 \%$ of statements of cluster 5.b4) provide positive experience with creating materials for pupils in the form of electronic manuals, video tutorials and worksheets. The same amount of statements (12.9\%) form cluster 5.b5); respondents say in them that including specific technologies, mainly virtual educational environment, cloud environment, interactive whiteboard, but also spatial visualization and augmented reality in the lessons have proved successful (Prokýšek and Rambousek, 2012; Jeřábek, Prokýšek and Rambousek, 2013). The last cluster 5.b6) contains $11.3 \%$ of statements declaring good experience with an ongoing update of the educational content of the given field and reflection of the development in the ICT field.

It is necessary to emphasize that the numbers of the statements in individual clusters do not indicate directly the level of significance or importance of particular clusters. It is also necessary to emphasize the fact that due to the voluntary principle of the survey it was not possible to ensure the full representativeness of the sample comparable with a random selection since the selection of the respondents was primarily based on the teachers interested in the participation in the survey. The above presented findings cannot be therefore considered generally true. We may only relate them to the respondents of the survey and any generalization warrants caution.

\section{Case studies}

The case studies were coded and divided into the blocks according to the structure of the school description based on its tour, description of the equipment (information from the first and fourth study), classroom observation, discussions with pupils and an interview with a teacher. Within individual blocks of the study, the obtained data were analyzed through the cluster analysis method, during which the participants' statements and observation outcomes were grouped based on their similarity. In the individual blocks, dominant clusters covering observed facts were thus identified. The findings obtained through the case study method are as follows (Rambousek et al, 2013; Fuglík, 2014).

Teachers consider the current concept of FEP EE (Framework Educational Programme for Elementary Education) in the field of Information and Communication Technology as outdated, lacking a clear concept, not reflecting the development in the 
field and new requirements for the development of pupils' information technology competencies. They lean toward the considerable revision of its content and time allocation of the subject, or explicit integration of ICT and development of the competencies into other subjects.

Some teachers try to innovate the SEPs and adapt them to current trends. Another approach is to leave the SEPs in their original form and focus on the development of their own teaching materials and contents because there is a permanent shortage of up-to-date and high-quality materials for teaching ICT.

Better technology equipment in the classrooms and for teachers helps ICT to enter gradually into other subject as well. Educational applications are used less than before (they remain popular mainly in primary schools and in foreign language teaching). Real environment of the Internet using modern web browsers with HTML 5 support and other technologies connecting web environment to the usual workstation environment is becoming a didactical means increasingly. The gap between the online applications built on the Web 2.0 concept and the applications installed on workstations is narrowing.

Primary and lower-secondary school teachers use increasingly interactive technologies, most often financed from the European funds whereas they gradually turn away from the concept of using interactive whiteboards together with a digital projector. The increased use of LCD displays or other, cheaper, touchscreen technology for any surface based on eBeam technology is a general trend. Teachers use their technical equipment to prepare their own teaching contents. They share their successful contents and they work on their improvement along with other teachers within or outside the school, or they publish them on the Internet. Pupils also start getting involved increasingly well in the development of the materials.

Resources from projects and grants go also into the support of school ICT infrastructure. Schools manage workstations based on Windows and Linux operational systems as a full solution not only for school work. On some workstations, pupils can choose the operating system during the startup process without influencing the lesson objectives. In terms of servers, the installations of Linux system prevail, most frequently Debian distribution, or schools are switching to full cloud solutions based on Google Apps for education.

It goes without saying that a local network distribution and a high-quality Internet connection can be nowadays used by both pupils and teachers in the learning process. The connection is usually ensured by local providers. Pupils can use computer labs also for other study, work or entertainment purposes. School WiFi networks available also for pupils make it easier for pupils to use their own smart phones or tablets. The rules for using school networks are usually based on mutual trust, filters and other third party solutions are not often reliable and they are not fit for purpose. Mostly, school staff participates in the administration of ICT; external staff provides only occasional technical support for school infrastructure or server administration.

Websites are a usual part of school presentation, the content of which is no longer limited only to providing information. Websites are becoming part of school life, its culture and they help to illustrate its overall atmosphere. On the websites, photographs and videos from school events but also common everyday activities are published; teachers establish their own subject websites and blogs with study materials and tasks. Classes also establish their own websites. Both pupils and teachers are involved in creating their content. Parents start contributing as well. Easily accessible CMS tools, often integrated directly within the web administration, are used to publish information. External subjects participate in web development only exceptionally.

Mutual communication with parents within and outside school is done mostly by e-mail. Attempts to transfer this communication into the environment of closed groups in social networks are not isolated. There are no formal rules for the communication between a teacher and parent in schools. The originally widespread application Bachelors for school administration is replaced by modern online systems, among which School Online or iSchool.cz belong, which are commonly used for the school register administration, preparation of the school report, but also as a substitute for pupil's Record Book. Schools consider an electronic class registers as well.

ICT is becoming a tool for Czech and international projects in schools. Technologies are used for mutual communication of the participants and international cooperation. eTwinning is a fairly widespread activity, boarder schools use actively a cooperation with foreign language subjects. E-learning in the school environment has not proved very successful in relation to a pupil; nevertheless it is used for teachers' formal and informal education, which the schools often prepare by themselves. For these purposes, Moodle is used as a platform. The use of e-portfolio is starting to be discussed in schools. Schools are aware of its significance in terms of longitudinal evaluation and pupil's self-reflection and they consider various ways of its implementation (Fuglík and Černochová, 2012).

For each case study, there was allocated one day with a regular programme and teaching. Within the school visit, a detailed record of all that was found out was processed. The obtained data were processed by the same researcher, who carried out the research in school as well, with an ongoing supervision from other project researchers. The selection of the schools included in the list of candidates for the case study was based on ICT teachers' voluntary consent and we may thus suppose that case studies were realized in the schools, in which the issue of ICT receives special attention.

Ethical aspects of case studies were consulted with the school headmasters. The monitoring of the learning process was carried out by means of an observation and pupils were not in advance prepared for the observer's visit. In contrast, they were informed about the discussion, which was conducted during the lesson with the teacher present. It was realized with the aim to capture pupils' sensory perception and volitional processes. The questions were structured so that they would not make pupils shy and they would not be afraid to answer them truthfully.

\section{Discussion}

The above findings can be compared with the results of similarly oriented research project Research of Informatics Education 2006 (VIV06), which was carried out by the staff of the Faculty of Education at Charles University, Prague; with the support of the Ministry of Education, Youth and Sports, the Czech Republic. The research was focused on a wide area of informatics education within the primary and lower-secondary education in the Czech Republic. The research was based on a large explorative survey whose target group were the teachers of informatics subjects, or in other words, the teachers responsible for students' preparation in respect to informatics education and development of information technology competencies in schools. Relevant data were gathered from 930 respondents representing individual primary and lower-secondary schools. The above findings correspond with the results of the project 
VIV06 and can indicate only minor shifts. Based on comparison with the results VIV06, it can be stated a significant increase of the importance of the skill concerning the assessment of the seriousness and credibility of electronic information resources and a significant decrease of the importance of the skill concerning making and editing new documents in the text editor. It can also note a positive trend, which is the gradual shift of ICT skills of teachers of informatics learning toward higher levels (Rambousek et al, 2007).

Currently the development of digital competences also addressed several international surveys, for example, in research International Adult Literacy Survey or IALS Programme for International Assessment of Adult Competencies PIAAC (http://www.piaac.cz/vystupy). Development of information and computer skills of children has recently become a subject of interest in the project International Computer and Information Literacy Study ICILS 2013, which was attended by 19 states and the Czech Republic 170 schools, 3,100 students and 2,150 teachers. Among the interesting results of the project belong, that the pupils of the Czech Republic achieve the best result from all participating countries, or that boys prefer their digital skills develop themselves, while girls learn their digital skills in school and in the family (http://www.icils.cz/articles/files/ ICILS_2013_Narodni_zprava_CZE.pdf).

The research project provides not only the actual findings concerning the characteristics and content of digital literacy education and ways to develop the digital competencies of pupils in primary schools, but from a distance of several years from the similarly conceived research VIV 06 also identify differences or developments in many of the areas. The project results may also be beneficial in terms of better preparation in the direction of the development of the digital skills of children in schools and teachers training. Finally, it should be emphasized that the detection achieved by the above methods of the survey and case studies should be viewed with some limitation stemming from the nature of the research, which could not work with a random selection due to the volunteer principle, or respondents' interest in cooperation. The achieved results cannot be therefore considered as generally true. They can only be related to the respondents of the research and any generalization warrants caution.

\section{Conclusion}

The findings of the survey and case studies applied in the second stage of the research, complemented the other results in the first phase of research applied methods, primarily in terms of evaluation of curricular materials and conditions for effective implementation of digital literacy in primary schools (Rambousek and Štípek, 2014; Fuglík, 2014).

Most of the respondents consider the content of FEP EE in the educational field of Information and Communication Technologies as too general and half of them criticize its concept due to the lack of current content or overall inadequacy of the concept. Above all, the document should be modified in terms of the increase of a time allocation, better specification of the content and in terms of its extension and innovation.

In the area of Information Communication Technologies, SEPs are supplemented or modified primarily in terms of extension, enrichment and innovation of the curriculum. SEPs are also modified with the aim to provide informatics subjects and topics more time considering their importance for the development of particular pupils' competencies. Generally, respondents consider the time allocation for the compulsory informatics subject in the school curriculum as insufficient and at the same time they do not support its merging with other subjects.

Respondents declare that they manage to achieve the goals and intentions of SEP to build and develop pupils' information technology competencies, in many cases also with the help of other subjects. Above all, they see adequate technical equipment and teachers' qualification and their level of expertise as necessary conditions for achieving goals and intentions of SEP from the standpoint of building and developing pupils' information technology competencies. In contrast, they identify insufficient technical equipment and a lack of finances for its development and teachers' low qualification and their level of expertise as the main obstacles.

As other obstacles they identify a low time allocation for the informatics subject, pupils' lack of interest and reluctance and colleagues' and leadership's weak support. In the lessons of a compulsory informatics subject, respondents usually apply a combination of methods and teaching techniques, or they encourage pupils' practical work if possible with outcomes interesting for pupils, or useful in practice. Individual practical work, individual approach to pupils, supporting pupils' interest in learning and creating practical outcomes have proved successful.

Overall, based on the findings of the case studies, in relation to the monitored curricular, process and organisation aspects of digital literacy education in primary and lower-secondary schools in the Czech Republic, and taking into account the above mentioned restriction concerning the representativeness of the sample, we may conclude that the development of pupils' digital competencies is not ensured only through compulsory informatics subjects in schools, though their role is dominant in this direction. The content of FEP EE in the educational field of Information and Communication Technologies is considered as extremely general and it is criticised primarily for the lack of up-to-date content. In the first place, the document should be modified in terms of the increase of time allocation, better specification of the content and in terms of its extension and innovation. Following these directions, schools try to modify and extend the concept of FEP EE in their school educational programmes as well.

Although a platform and application approach prevail in school practice, a lot of teachers find it important to work in various environments so that pupils' competencies development will not be dependent on a specific platform and application since easy adaptation to new technologies is possible only when pupils' understanding is based on invariable hyper platform and beyond application approaches. The implementation of digital technologies and activities supporting pupils' information technology competencies development into school life and educational environment thrives primarily in the fields that do not place extra time or qualification demands on teachers. Besides the content orientation of informatics subjects, appropriate technological equipment, and teachers' qualification and expertise level, it is also broad implementation of digital technologies and activities supporting pupils' digital competencies development into various subjects, educational environment and school life that is seen as a condition for effective pupils' digital competencies development.

\section{References}

Ala-Mutka, K. (2011). 'Mapping Digital Competence: Towards a Conceptual Understanding'. Luxembourg: Publications Office of the European Union. Available: http://ftp.jrc.es/EURdoc/ JRC67075_TN.pdf. 
Ala-Mutka, K., Punie, Y and Redecker, Ch. (2008). 'Digital Competence for Lifelong Learning'. Luxembourg: Institute for Prospective Technological Studies, European Commission.

European Commission. (2008). 'Commission Staff Working Document. The use of ICT to support innovation and lifelong learning for all. A report on progress, SEC(2008)2629 final'. Brusels: Commision of Europian Communities.

European Commission. (2013). 'Opening up Education: Innovative teaching and learning for all through new Technologies and Open Educational Resources'. Brussels: Commision of Europian Communities. Available: http:// ec.europa.eu/education/news/doc/openingcom_en.pdf.

European Parliament and the Council. (2006). 'Recommendation of the European Parliament and of the Council of 18 December 2006 on key competences for lifelong learning', Official Journal of the European Union, L394/310.

Ferrari, A. (2012). 'Digital Competence in Practice: An Analysis of Frameworks'. Luxembourg, European Commission. Available: http://ftp.jrc.es/EURdoc/JRC68116.pdf.

Ferrari, A. (2013). DIGCOMP: 'A Framework for Developing and Understanding Digital Competence in Europe'. Luxemburg: Europion Commition. Available: http://ftp.jrc.es/EURdoc/ JRC83167.pdf.

Fuglík, V. (2014). 'Case Studies of the Implementation of ICT and IT Competencies Development in Primary and LowerSecondary Schools', Proceedings of 11th International Conference on Efficiency and Responsibility in Education (Erie 2014). Prague: Czech University of Life Sciences in Prague, pp. 139-146.

Fuglík, V. and Černochová, M. (2012). 'Research Findings on Implementing Student Portfolios into Teacher Education', Proceedings of 9th International Conference on Efficiency and Responsibility in Education (Erie 2012). Prgue: Czech University of Life Sciences Prague, pp. 130-139.

Jeřábek, T., Prokýšek, M. and Rambousek, V. (2013) 'Using augmented reality in education', Proceedings of 10th International Conference on Efficiency and Responsibility in Education (Erie 2013). Prague: Czech University of Life Sciences Prague, pp. 256263. ISBN 978-80-213-2378-0.

OECD DeSeCo (2005). 'The Definition and Selection of Key Competencies: Executive Summary'. 2005. Available: http:// www.oecd.org/pisa/35070367.pdf.

Prokýšek, M. and Rambousek, V. (2012) 'Efficiency of the application of spatial visualization in instruction in relation to spatial intelligence', Proceedings of 9th International Conference on Efficiency and Responsibility in Education (Erie 2012). Prague: Czech University of Life Sciences Prague, pp. 481488.

Rambousek, V. and Štípek, J. (2014). 'Research findings on teachers of informatics subjects in elementary schools', Proceedings of 11th International Conference on Efficiency and Responsibility in Education (Erie 2014). Prague: Czech University of Life Sciences Prague, pp. 631-639.

Rambousek, V., Štípek, J., Procházka, J., Neumajer, O. and Mudrák, D. (2007). 'Výzkum informační výchovy na základnich školách'. Plzeň: Koniáš.

Rambousek, V., Štípek, J. and Wildová, R. (2015). 'ICT competencies and their development in primary and lowersecondary schools in the Czech Republic', 5th ICEEPSY International Conference on Education and Educational Psychology, Procedia-Social and Behavioral Sciences. Istanbul:
Turkey, pp. 535-542. doi:10.1016/j.sbspro.2015.01.158

Rambousek, V., Štípek, J., Procházka J. and Wildová, R. (2014) 'Research on ICT literacy education in primary and lower secondary schools in the Czech Republic', Procedia-Social and Behavioral Sciences Journal, pp. 1263-1269. doi:10.1016/j. sbspro.2014.05.218

Rambousek, V., Štípek, J., Procházka, J., Černochová, M., Fuglík, V. and Vaňková, P. (2013). 'Rozvoj informačně technologických kompetenci na základních školách'. Praha: České vysoké učení technické v Praze.

Štípek, J., Rambousek, V. and Procházka, J. (2013a). 'ICT literacy education and teachers' ICT competencies', Proceedings of 10th International Conference on Efficiency and Responsibility in Education (Erie 2013). Prague: Czech University of Life Sciences Prague, pp. 587594.

Štípek, J., Rambousek, V. and Procházka, J. (2013b). 'Primary findings of the research on ICT literacy education pupils' and teachers' information technology competencies in primary and lower secondary schools', Journal on Efficiency and Responsibility in Education and Science, 6(4), pp. 245-264. doi: 10.7160/eriesj.2013.060403

UNESCO. (2005). 'Information and communication technologies in schools: a handbook for teachers or how ICT Can Create New, Open Learning Environments'. France: Division for Higher Education UNESCO. Available: http:// unesdoc.unesco.org/images/0013/001390/139028e.pdf. 